\title{
The emergence of surface-based Arctic amplification
}

\author{
M. C. Serreze ${ }^{1}$, A. P. Barrett ${ }^{1}$, J. C. Stroeve ${ }^{1}$, D. N. Kindig ${ }^{1}$, and M. M. Holland ${ }^{2}$ \\ ${ }^{1}$ National Snow and Ice Data Center, Cooperative Institute for Research in Environmental Sciences University of Colorado, \\ Boulder, CO, USA \\ ${ }^{2}$ Climate and Global Dynamics Division, Earth and Sun Systems Laboratory National Center for Atmospheric Research \\ Boulder CO, USA
}

Received: 12 June 2008 - Published in The Cryosphere Discuss.: 16 July 2008

Revised: 18 November 2008 - Accepted: 26 December 2008 - Published: 4 February 2009

\begin{abstract}
Rises in surface and lower troposphere air temperatures through the 21 st century are projected to be especially pronounced over the Arctic Ocean during the cold season. This Arctic amplification is largely driven by loss of the sea ice cover, allowing for strong heat transfers from the ocean to the atmosphere. Consistent with observed reductions in sea ice extent, fields from both the NCEP/NCAR and JRA-25 reanalyses point to emergence of surface-based Arctic amplification in the last decade.
\end{abstract}

\section{Introduction}

The concept of Arctic amplification, articulated by Manabe and Stouffer (1980) and a near universal feature of climate model simulations (Holland and Bitz, 2003), is that rises in surface air temperature (SAT) in response to increasing atmospheric greenhouse gas (GHG) concentrations will be larger in the Arctic compared to the Northern Hemisphere as a whole. Model-projected Arctic amplification is focused over the Arctic Ocean (Serreze and Francis, 2006). As the climate warms, the summer melt season lengthens and intensifies, leading to less sea ice at summer's end. Summertime absorption of solar energy in open water areas increases the sensible heat content of the ocean. Ice formation in autumn and winter, important for insulating the warm ocean from the cooling atmosphere, is delayed. This promotes enhanced upward heat fluxes, seen as strong warming at the surface and in the lower troposphere. This vertical structure of temperature change is enhanced by strong low-level stability which inhibits vertical mixing. Arctic amplification is not prominent in summer itself, when energy is used to melt remaining sea ice and increase the sensible heat content of the upper ocean,

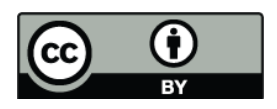

Correspondence to: M. C. Serreze (serreze@kryos.colorado.edu) limiting changes in surface and lower troposphere temperatures. Loss of snow cover contributes to an amplified temperature response over northern land areas, but this temperature change is not as pronounced as over the ocean.

These simulated aspects of Arctic amplification are illustrated in Fig. 1 using results from the Community Climate System Model, version 3 (CCSM3). This model is known for its good simulation of Arctic sea ice conditions and change over the late 20th and early 21 st century (Holland et al., 2006; Stroeve et al., 2007). Figure 1a shows monthly SAT changes (A1B emissions scenario for the 21st century, observed GHG concentrations for the 20th century) from 1980-2100, relative to 1979-2007 over the Arctic Ocean. This is the same domain used in the recent Arctic Ocean energy budget analysis of Serreze et al. (2007a). The pattern of cold season warming growing with time is obvious. Figure $1 \mathrm{~b}$ shows the zonally-averaged latitude by height cross section of OctoberMarch temperature anomalies for the mid-century decade 2050-2059. Consistent with the dominant impacts of an anomalous surface heat source, the high-latitude warming becomes stronger from the lower troposphere towards the surface, a pattern that emerges by 2020-2029 and grows in strength as the decades pass. The largest Arctic anomalies in Fig. 1b are depicted over the pole, not at lower Arctic latitudes where the simulated September ice loss relative to 1979-2007 is most pronounced. This apparent poleward focus of anomalies is an artifact of zonal averaging, through which prominent positive temperature anomalies associated with reduced September ice cover, most pronounced north of Siberia in CCSM3, are compensated by smaller anomalies at other longitudes but similar latitudes, such as over the Northern North Atlantic. By 2070-2079, CCSM3 depicts a nearly ice-free Arctic Ocean for September, such that the pole-focused maximum in warming depicted in the zonal mean more closely reflects the spatial pattern of simulated anomalies. 

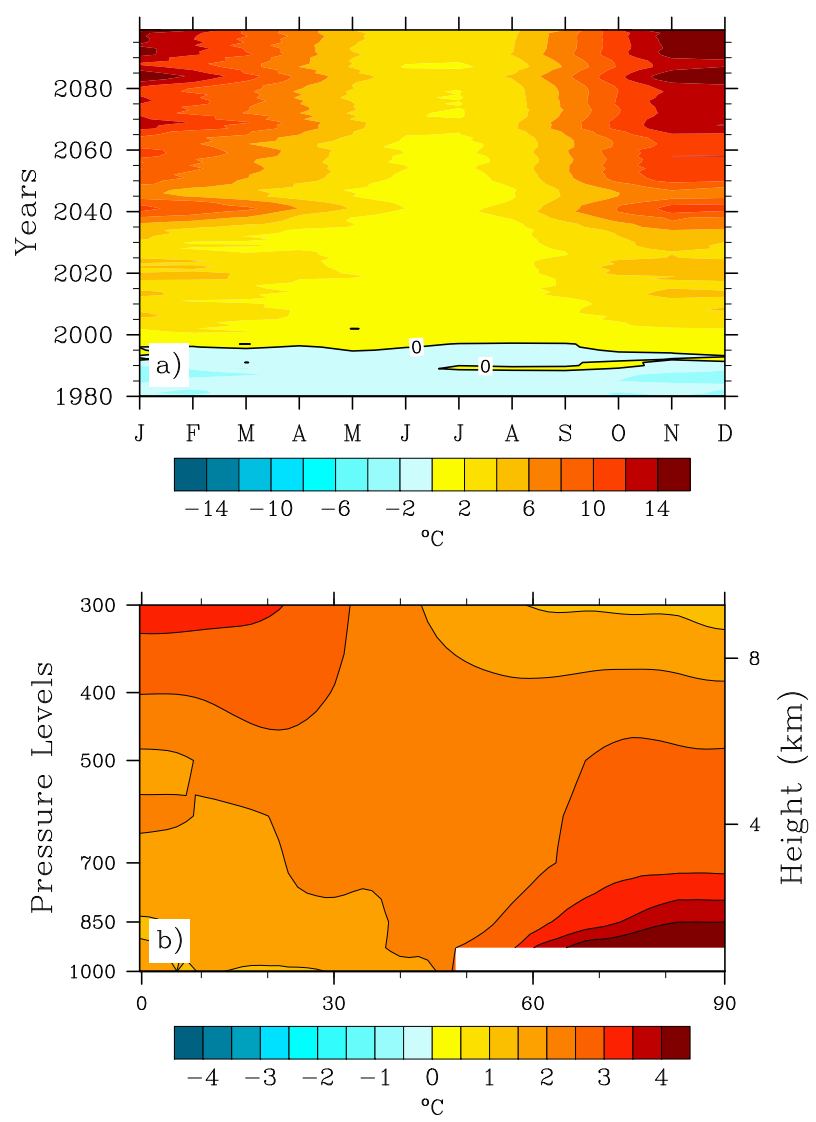

Fig. 1. NCAR CCSM3 depictions of: (a) near surface ( $2 \mathrm{~m}$ ) temperature anomalies by month and year over the Arctic Ocean, and (b) latitude by height dependence of zonally-averaged October-March temperature anomalies for 2050-2059. Anomalies are relative to 1979-2007 means. See Fig. 3 for definition of the Arctic Ocean domain.

Our analysis of 16 models participating in the Intergovernmental Panel on Climate Change Fourth Assessment Report (IPCC-AR4) reveals consistency in the basic seasonality and vertical structure of this 21 st century warming, but with different timings, magnitude and spatial patterns of change (model output is available at the Program for Climate Model Diagnosis and Intercomparison, http://www-pcmdi.llnl.gov/ about/index.php). While this in part reflects strong model-tomodel scatter in rates and spatial patterns of ice loss through the 21st century (Arzel et al., 2006; Zhang and Walsh, 2006; Stroeve et al., 2007), a suite of other factors likely also contributes, including differences in patterns of horizontal atmospheric heat transport, vertical mixing and the radiative effects of clouds and water vapor.

Pronounced decreases in Arctic sea ice extent (typically defined as the area of the ocean with an ice concentration of at least $15 \%$ ) have been observed since the advent of routine satellite monitoring in 1979. Negative trends over the satellite record, while largest at the end of the melt season in September, characterize all months (Serreze et al., 2007b). Exceptional September extent minima have characterized every year since 2002, with 2007 setting a record low (Stroeve et al., 2008). The 2008 September minimum was the second smallest extent on record. Including 2008, the linear trend in September ice extent over the satellite record stands at $-11.7 \%$ per decade (http://nsidc.com/arctiseaicenews). Attendant thinning of the ice pack finds support in satellite observations pointing to declining coverage of perennial (multiyear) ice (Nghiem et al., 2006; Kwok, 2007) and results from an ice age tracking algorithm (Maslanik et al., 2007b).

Zhang and Walsh (2006) note that essentially all coupled models participating in the IPCC-AR4 show declining sea ice over the period of observations. While this is strong evidence of a role of GHG forcing on the observed trend, Stroeve et al. (2007) find that depending on the time window for analysis, none or few simulations have a September trend as large as observed. One explanation is that natural variability in the observed coupled system has been a very strong player. Changes in spring cloud cover (Francis and Hunter, 2006), wind-driven alterations in sea ice circulation and ice age associated with the Northern Annular Mode and other patterns of atmospheric variability (Thompson and Wallace, 1998; Rigor et al., 2002; Rigor and Wallace, 2004; Maslanik et al., 2007a) and altered ocean heat transport (Polyakov et al., 2005; Shimada et al., 2006) have all been implicated in the observed ice retreat. Another explanation is that the models as a group under-represent the sea ice sensitivity to $\mathrm{GHG}$ loading (Stroeve et al., 2007).

Given pronounced observed decreases in Arctic sea ice extent, it is reasonable to expect that Arctic amplification is emerging. Graversen et al. (2008) examined temperature trends as a function of latitude and height over the period 1979-2001, based on fields from the European Centre for Medium-Range Weather Forecasts (ECMWF) ERA40 reanalysis (Uppala et al., 2005), JRA-25, a recent effort of the Japanese Meteorological Agency (Onogi et al., 2005, 2007), and the National Centers for Environmental Prediction/National Center for Atmospheric Research (NCEP/NCAR, hereafter NCEP) reanalysis (Kalnay et al., 1996). While ERA-40 documents larger positive trends in surface temperatures in the Arctic by comparison with lower latitudes in all seasons except summer, the largest Arctic trends in winter and summer lie above the surface. The largest Arctic trends in spring lie near the surface, while in autumn, Arctic trends aloft are comparable to those at the surface. Based on this complex vertical structure, they argue that much of the recent Arctic warming is linked to processes other than sea ice and snow cover loss, in particular, increased horizontal atmospheric energy transport into the Arctic. Trends for the same period from JRA-25 have roughly the same vertical distribution but generally smaller magnitudes compared to ERA-40. Differences in Arctic patterns between the two reanalyses are most pronounced in winter, spring and autumn. By contrast, Arctic trends from NCEP 
are most positive at the surface for all seasons but summer, with this surface maximum most pronounced in autumn and (like the pattern in Fig. 1b) strongest at the pole.

Based on analysis of output extending through 2007 (hence including more recent years) from the NCEP and JRA-25 reanalyses, the satellite-derived sea ice record, and comparisons with simulated SAT variability based on CCSM3, we argue that Arctic amplification with a clear surface maximum associated with sea ice loss has emerged.

\section{The NCEP/NCAR and JRA-25 reanalyses}

Atmospheric reanalyses are retrospective forms of numerical weather prediction. Fields such as pressure heights and tropospheric temperature blend a short term atmospheric forecast with observations and are the most reliable. Fields for variables such as terms of the surface energy budget are less reliable as they are not directly influenced by observations of that variable. Temporal inconsistencies may arise due to changes in observing networks. Fields from the NCEP reanalysis extend from 1948 through the present, but those since 1979, corresponding to the advent of modern satellite data streams, are of higher quality. The JRA-25 effort starts in 1979 and is also updated. ERA-40 starts in 1958, but unfortunately ends in July 2002. We hence rely on data from NCEP and JRA-25 over the period 1979-2007. The horizontal model spectral resolution of NCEP is T62, which is about $210 \mathrm{~km}\left(\right.$ or $2^{\circ}$ ). The horizontal model spectral resolution of JRA-25 is T106, which is about $120 \mathrm{~km}$ (or $1.25^{\circ}$ ). Emphasis is placed on results from NCEP; comparisons are made with JRA-25 output as needed.

NCEP is a first-generation reanalysis effort, initiated in the early 1990s. It has known shortcomings. Available data sources over northern high latitudes include temperature profiles from the TIROS Operational Vertical Sounder (TOVS) and advanced TOVS (ATOVS) systems aboard polar-orbiting NOAA satellites, the extensive rawinsonde network surrounding the Arctic Ocean and aircraft reports. The model can also assimilate marine surface reports of winds, pressure and temperature. Since 1979, surface pressure and temperature data over the ice covered Arctic Ocean are available from arrays of drifting buoys (surface data are not assimilated over land). However, determining what is actually assimilated at a given time and location can be difficult for users to assess. TOVS and ATOVS retrievals are known to be particularly problematic over the cloudy Arctic, and many of these profiles are rejected.

The NCEP system uses observed sea ice, but only two states, ice covered and ice free, are considered, based on a $55 \%$ concentration threshold. A constant ice thickness of $2 \mathrm{~m}$ is assumed. Sea ice albedo is a function of surface skin temperature and snow cover. The $2 \mathrm{~m}$ temperature (SAT) represents interpolation between the lowest model (sigma) level and the skin temperature, the latter is specified over open ocean from available sea surface temperature data and prognostically determined over land and sea ice. Sea ice extent since 1979 is based on retrievals from the space-borne Scanning Multichannel Microwave Radiometer (SMMR, 19791987) and the Special Sensor Microwave/Imager (SSM/I, 1987-present) (Kalnay et al., 1996).

Different sea ice analyses were used during the period 1998-2004, leading to some mismatches between the sea ice analyses and model regarding identification of ocean versus land points. This can be seen in SAT and related variables (such as upwelling longwave radiation from the surface) being erroneously high over some polar grid cells, most obvious during the cold season. Analyses that follow consider these problem grid cells as missing in all months. Problem cells were identified as those for which the difference between monthly means of upwelling longwave radiation for the periods 1979 to 1996 and 1998 to 2001 exceeded $10 \mathrm{Wm}^{-2}$. The 1998 to 2001 mean, instead of 1998 to 2004, proved to be the most effective identifier for problem cells. This is a conservative criterion that may result in valid cells being excluded. The screening process resulted in 52 cells being excluded from the 652 cell Arctic Ocean domain (see Fig. 3). However, results that follow below are not significantly different from those obtained when problem cells are included.

Another change in the sea ice analysis in August 2004 led to similar problems in coastal regions but a fix was adopted and the affected files repaired. Yet further changes were made in August 2006, including (but not limited to) replacing the NASA Team 1 sea ice algorithm (applied to the SSM/I brightness temperatures) with the Team 2 algorithm (B. Grumbine, NCEP, personal communication, 2007). Inconsistencies may also arise due to (among other issues) transition from TOVS to ATOVS between 1998 and 2001 (K. Trenberth, NCAR, personal communication, 2007). For a description of these and other problems and issues, see http://www.cdc.noaa.gov/cdc/reanalysis/problems. shtml and http://www.cpc.ncep.noaa.gov/products/wesley/ reanalysis.html\# problem.

JRA-25 is a much more recent effort, initiated in 2001, and considerably more advanced than the NCEP effort. Onogi et al. $(2005,2007)$ provide details. Briefly, while JRA-25 draws from the same basic satellite and conventional data streams as NCEP and ERA-40, the system assimilates satellite radiances rather than retrieved profiles, an approach which avoids trends and variability due to changes introduced in satellite data processing over the years. JRA-25 has higher vertical resolution than NCEP, and assimilates both marine and terrestrial surface temperatures. Satellite-derived sea ice is treated not as a slab but as fractional ice cover. While we are not aware of inconsistencies in the sea ice analysis such as those identified in NCEP, this does not mean that none exist. 

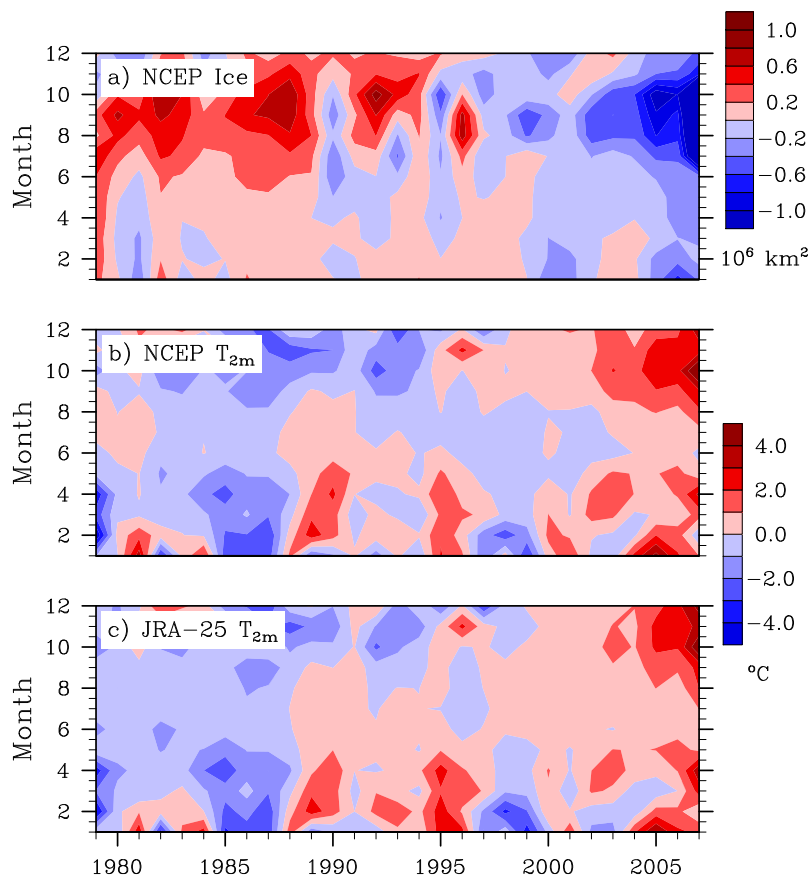

Fig. 2. Anomalies by year (x axis) and month (y axis) from 19792007 of (a) sea ice extent from the NCEP reanalysis, (b) $2 \mathrm{~m}$ (surface air) temperature, from the NCEP reanalysis, (c) $2 \mathrm{~m}$ (surface air) temperature from the JRA-25 reanalysis, all for the same Arctic Ocean domain used in Fig. 1a and shown in Fig. 3. Anomalies are referenced to 1979-2007.

\section{Results}

Figure 2a shows anomalies in Arctic Ocean sea ice extent as a function of year and month, as given in the NCEP reanalysis. Corresponding anomalies in SAT from NCEP follow in Fig. 2b. Results are for the same Arctic Ocean domain used for Fig. 1a and shown in Fig. 3. Spurious coastal grid cells have been screened out. The prominent loss of ice in summer and early autumn relative to other months is obvious. The evolution of SAT is quite different. Pointing to the moderating effects of melting ice and heat uptake in open water areas, changes in summer temperature have been modest. By sharp contrast, temperature anomalies in autumn have shifted from predominantly negative through the mid 1990s to strongly positive in the later part of the record. Positive anomalies are especially large in the last two years of the record and for October (exceeding $3^{\circ} \mathrm{C}$ ), one month after the seasonal sea ice minimum. Positive anomalies also emerge for winter, but with a less coherent pattern than for autumn and a peak in January 2005.

To assess the impacts of the $55 \%$ ice concentration cutoff and potential problems with the changing sea ice analyses in the NCEP data, a plot like Fig. 2a was compiled using data from the National Snow and Ice Data Center (NSIDC) sea ice index (http://nsidc.org/data/seaice_index/).
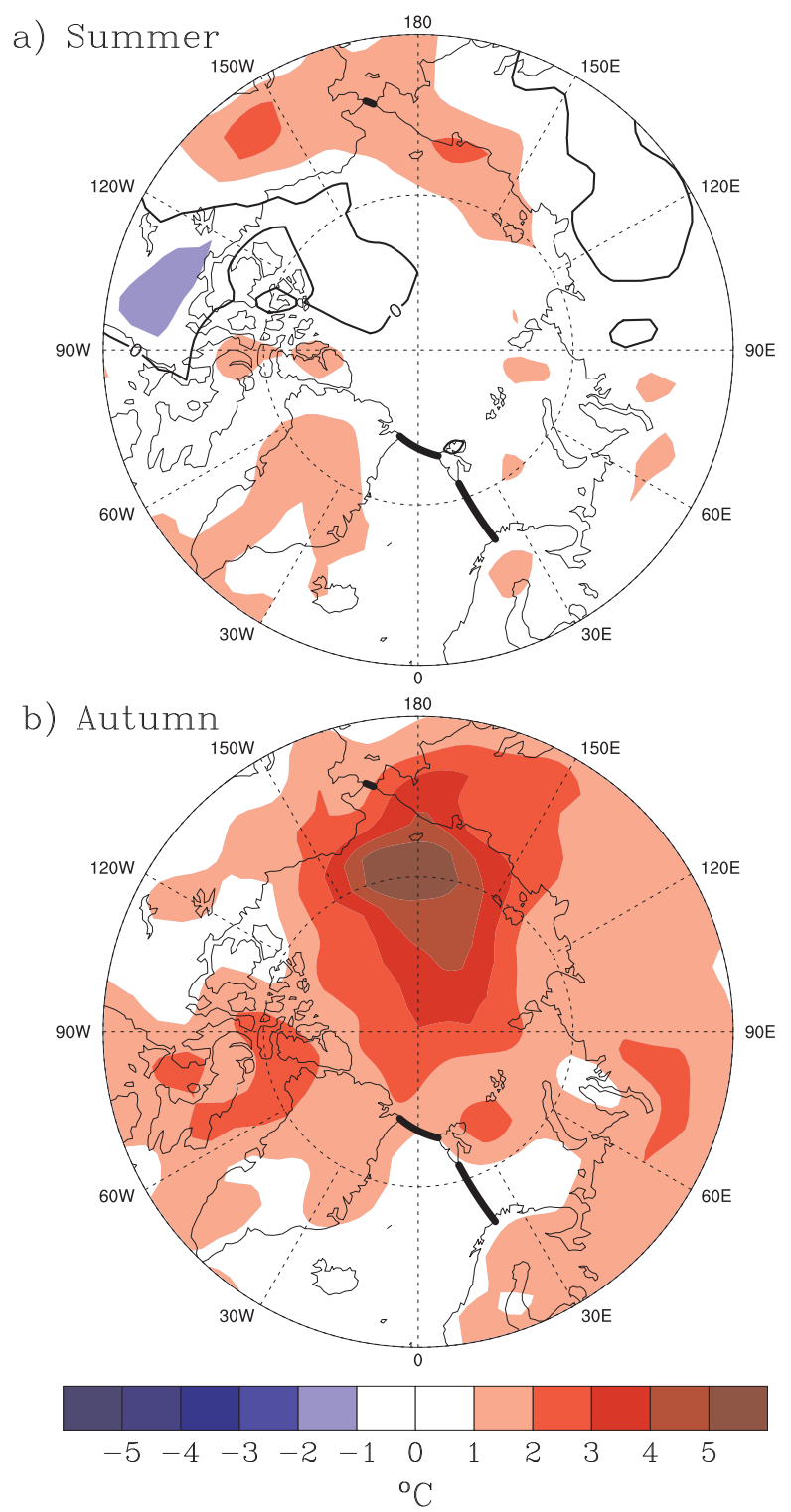

Fig. 3. Anomalies in NCEP surface air temperature for 20032007, relative to 1979-2007 means for (a) summer, defined as JuneAugust and (b) autumn, defined as September-November. Boundaries of the Arctic Ocean domain used to compile Figs. 1a and 2 are defined by the major oceanic straits (bold dark lines), the Eurasian and Alaskan coasts, and the northern boundaries of the Canadian Arctic islands and Greenland.

This gridded monthly product, provided at $25 \mathrm{~km}$ resolution, uses the NASA Team 1 algorithm throughout the period of record and a $15 \%$ concentration threshold (the same as used in Serreze et al., 2007b and many other studies). The resulting plot has the same features as Fig. 2a. Monthly ice extent anomaly time series from NCEP and NSIDC over the period 1979-2007, even when including the spurious grid cells in the NCEP record noted earlier, correlate at 0.98 at the $95 \%$ 
confidence interval. If known changes in the sea ice analyses and the transition from TOVS to ATOVS had prominent impacts on SAT, these would appear in Fig. $2 \mathrm{~b}$ as prominent non-climatic jumps. There is no compelling evidence of such features. We use the NCEP sea ice fields in compiling Fig. 2a rather than NSIDC fields to be consistent with the use of NCEP air temperatures.

Potential impacts of the constant $2 \mathrm{~m}$ ice thickness used in the NCEP reanalysis were addressed via atmosphere only simulations with CCSM3. SAT was assessed from runs with seasonally ice-free conditions (obtained from a late 21 st century simulation) and late 20th century ice conditions, in both cases assuming a constant $2 \mathrm{~m}$ ice thickness when ice is present. The difference between the two runs was then computed. SAT was also computed for runs with seasonally icefree and late 20th century conditions, but both with variable ice thickness (when present). Differences in SAT between seasonally ice-free conditions and late 20th century sea ice conditions are similar for runs with constant $2 \mathrm{~m}$ ice thickness and variable ice thickness. Allowing for variable ice thickness (thinner ice) increases the warming, but only by a small amount relative to the runs using constant ice thickness. This indicates that most of the increase in mean annual (and autumn) SAT over the Arctic associated with ice loss is due to the ice extent change and not changes in thickness. In other words, based on evidence from the CCSM3 simulations, the simple ice/no ice designation in NCEP captures the primary source of SAT change associated with declining sea ice. For comparison, Fig. 2c shows the evolution of SAT anomalies for the same domain and with respect to the same 1979-2007 base period from JRA-25. Recall that JRA-25 makes used of a fractional sea ice cover. The SAT evolution in JRA-25 is very similar to that shown by NCEP, with strong autumn warming in recent years standing out. The major difference is that NCEP shows a predominance of small negative anomalies in summer from the early 1990s through about 2003 compared with mostly small positive anomalies in JRA-25.

Figure 3 depicts spatial patterns of high latitude (north of $60^{\circ} \mathrm{N}$ ) SAT anomalies for the contrasting summer (Fig. 3a) and autumn (Fig. 3b) seasons from NCEP, averaged for the last pentad of the time series, 2003-2007. The modest positive anomalies over the Arctic Ocean in the summer months (June through August) depicted in Fig. 2b reflect compensation between positive values of $0.5-1.5^{\circ} \mathrm{C}$ along and north of the Eurasian coast and small negative anomalies over the Beaufort Sea north of Alaska. By sharp contrast, autumn (September through November) shows positive anomalies over almost all of the north polar region, but peaking at over $5^{\circ} \mathrm{C}$ north of Alaska and Eastern Siberia (Beaufort and Chukchi seas), where recent declines in September sea ice extent have been especially pronounced. The corresponding anomaly pattern from JRA-25 is very similar (not shown).

Note that positive anomalies exceeding $3^{\circ} \mathrm{C}$ in Fig. $3 \mathrm{~b}$ (and as also seen in JRA-25) extend well into the central

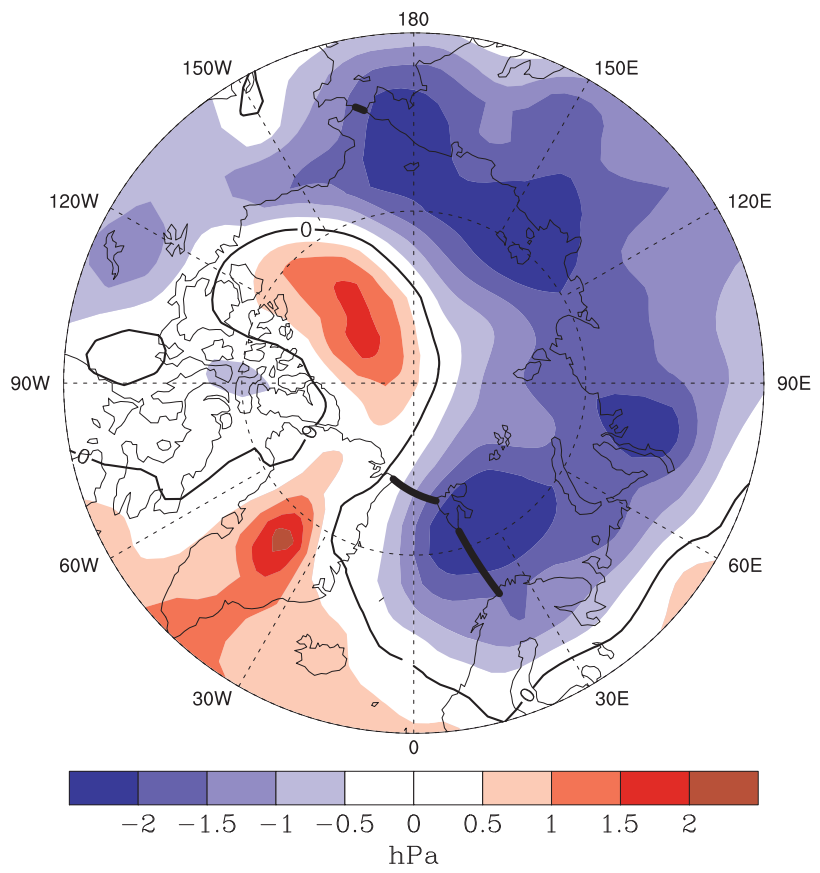

Fig. 4. Anomalies in NCEP sea level pressure (hPa) for autumn (September-October) for the pentad 2003-2007, relative to 19792007 means.

Arctic Ocean where sea ice was present even in September 2007. This argues for combined effects of sea ice loss and atmospheric circulation. For the long-term autumn mean, the region between the western Canadian Arctic Islands and eastern Siberia is characterized by a weak ridge in the sea level pressure (SLP) field. However, the anomaly pattern for autumn 2003-2007 (Fig. 4) has above average SLP centered over the Canada Basin at about $80 \mathrm{~N}, 225^{\circ} \mathrm{E}$ (up to $+1.5 \mathrm{hPa}$ ) and below average SLP along the Siberian coast (up to $-2.5 \mathrm{hPa}$ ). While the location of the maximum temperature anomalies in Fig. $3 \mathrm{~b}$ is consistent with open water promoting upward vertical heat fluxes, the anomalous southerly geostrophic wind component between the high and low pressure anomalies will help to transport this heat poleward. The pattern will also enhance the transport of heat into the region from the south. This pressure anomaly pattern was especially well developed during the summer of 2007 , and clearly contributed to the extreme summer ice losses of that year (Stroeve et al., 2008). The pattern also persisted into autumn.

Impacts of reduced ice cover are strikingly documented in Fig. 5. The top part of the figure, based on NCEP data, is a vertical cross section (surface to $300 \mathrm{hPa}$ ) of autumn temperature anomalies for the pentad 2003-2007, relative to the base period 1979-2007. The cross section, which extends from $50^{\circ} \mathrm{N}$ to the pole along the date line and then from the pole southward to $50^{\circ} \mathrm{N}$ along the prime meridian, 


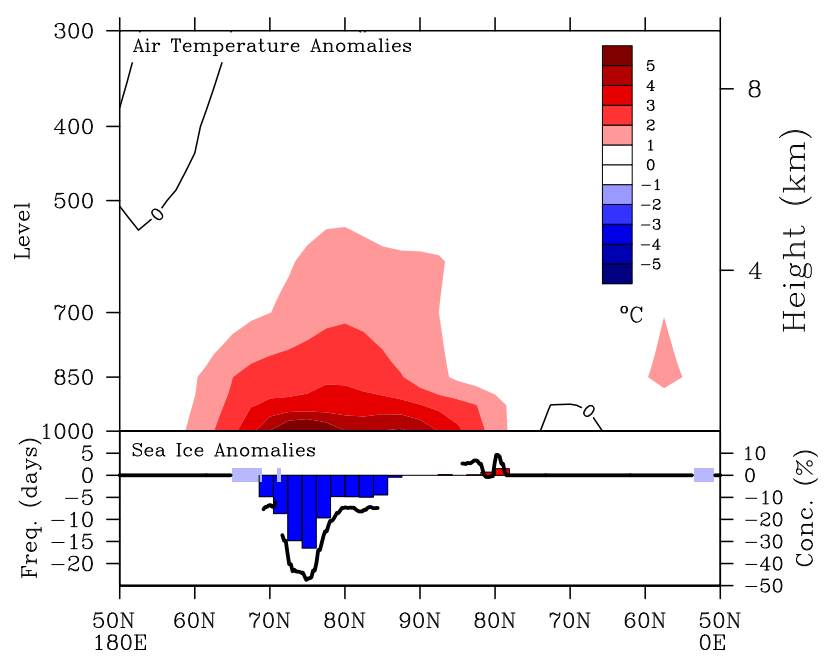

Fig. 5. Vertical (hPa) cross section of autumn (SeptemberNovember) temperature anomalies from NCEP for the pentad 2003-2007, relative to 1979-2007 means, along a transect (left to right) from $50^{\circ} \mathrm{N}$ to the pole along the date line and from the pole southward to $50^{\circ} \mathrm{N}$ along the prime meridian. Also shown for the same transect are corresponding September anomalies in the number of days with ice cover (ice concentration greater than 0.55 ) from NCEP (dark blue bars) and of ice concentration (black line) from the combined SMMR and SSM/I time series. As the SMMR record provides no coverage north of $85^{\circ} \mathrm{N}$, no concentration anomalies are plotted for these latitudes (NCEP assumes the presence of ice during the SMMR period). The light blue boxes along the zero anomaly line indicate land.

cuts almost through the center of the strongest autumn SAT anomalies shown in Fig. 3b. The bottom section of the figure plots September anomalies for the same pentad of the number of days with ice cover based on daily NCEP fields and of ice concentration from the gridded fields available from NSIDC. Recall that in NCEP, grid-cells with greater than $55 \%$ ice concentration are treated as ice covered.

There is a clear a pattern of positive temperature anomalies over the Arctic Ocean becoming larger towards the surface. The largest surface temperature anomaly of over $5^{\circ} \mathrm{C}$ is centered at $75^{\circ} \mathrm{N}, 180^{\circ}$ E. Consistent with Fig. 3b, smaller positive anomalies extend beyond the pole to $80^{\circ} \mathrm{N}, 0^{\circ} \mathrm{E}$. South of $80^{\circ} \mathrm{N}, 0^{\circ} \mathrm{E}$, anomalies are less than $1^{\circ} \mathrm{C}$ and become slightly negative at $75^{\circ} \mathrm{N}, 0^{\circ} \mathrm{E}$. The largest low-level temperature anomalies correspond closely to those latitudes with the largest negative anomalies in sea ice cover. The latitudinal structure of sea ice anomalies from the binary NCEP classification and expressed as ice concentration also closely match. On average, the ocean located beneath the largest surface temperature anomaly had 15 days less September sea ice cover (fifteen fewer days with less than 55\% concentration) for the period 2003 to 2007 compared to the long-term average. The correspondence between maximum temperature and sea ice anomalies, combined with the vertical structure of the warming, is consistent with the impacts of an anomalous surface heat source. Again, results based on JRA-25 (not shown) are very similar.

To further document the temporal evolution of the vertical structure of temperature changes over the Arctic Ocean, we compiled latitude by height cross sections of zonal-mean temperature for five pentads (1983-1987; 1988-1992; 19931997; 1998-2002; 2003-2007), again, expressed as anomalies with respect to 1979-2007. Cross sections were compiled for the four calendar seasons and by month using both NCEP and JRA-25 data.

The autumn cross sections for the last four pentads (Fig. 6) are revealing Looking first at results from NCEP, the cross section for 1983-1987 (not shown) is characterized by negative surface and tropospheric anomalies in high latitudes, strongest at the surface. Similar features appear in the cross section for 1988-1992. In the next pentad, 1993-1997, temperature anomalies are everywhere small. However, by 1998-2002, a pattern of high latitude warming, largest at the surface, has emerged. By the final pentad, 2003-2007, the pattern has become robust, with positive anomalies increasing from mid latitudes to the Arctic, with the Arctic anomalies increasing toward the surface. The cross sections based on JRA-25 tell the same basic story, the principal difference with respect to NCEP being the smaller magnitude of the anomalies, with a prominent surface-based signal appearing only in the final pentad.

The maximum surface and low-level warming in the NCEP zonal mean for the last pentad is at the pole. This curious feature is explained by having positive anomalies at all longitudes north of about $85^{\circ} \mathrm{N}$, contrasting with the lower Arctic latitudes where strong positive anomalies linked to ice loss are compensated by smaller anomalies at other longitudes. The pattern in the final JRA- 25 cross section is similarly explained, as is the less pronounced pole-centric pattern for the 1998-2002 pentad shown by NCEP. Such zonal averaging artifacts also help to explain the pattern of maximum positive trends at the pole in the NCEP data noted by Graversen et al. (2008). As discussed earlier, zonal asymmetry in anomalies also explains the pole maximum in warming seen in the CCSM3 cross section (Fig. 1b).

Imprints of atmospheric circulation are apparent in Fig. 6 as well as in results for other seasons. This reflects variability in the Northern Annular Mode and other patterns. For example, Fig. 6 shows that autumn warming extends through most (1998-2002) or part (2003-2007) of the troposphere in both reanalyses. In winter (not shown), the NCEP data for the most recent pentad show positive anomalies throughout the high-latitude troposphere, with a fairly strong feature at about $250 \mathrm{hPa}$, nearly as large as the surface anomaly in this season (maximized at 2 to $2.5^{\circ} \mathrm{C}$ at about $80^{\circ} \mathrm{N}$ ). In turn, the most recent pentad for summer in NCEP shows a maximum anomaly at $80^{\circ} \mathrm{N}$ of about $1.25^{\circ} \mathrm{C}$, not at the surface but at $925 \mathrm{hPa}$. Another warm summer feature is found at the pole at $300 \mathrm{hPa}$. 


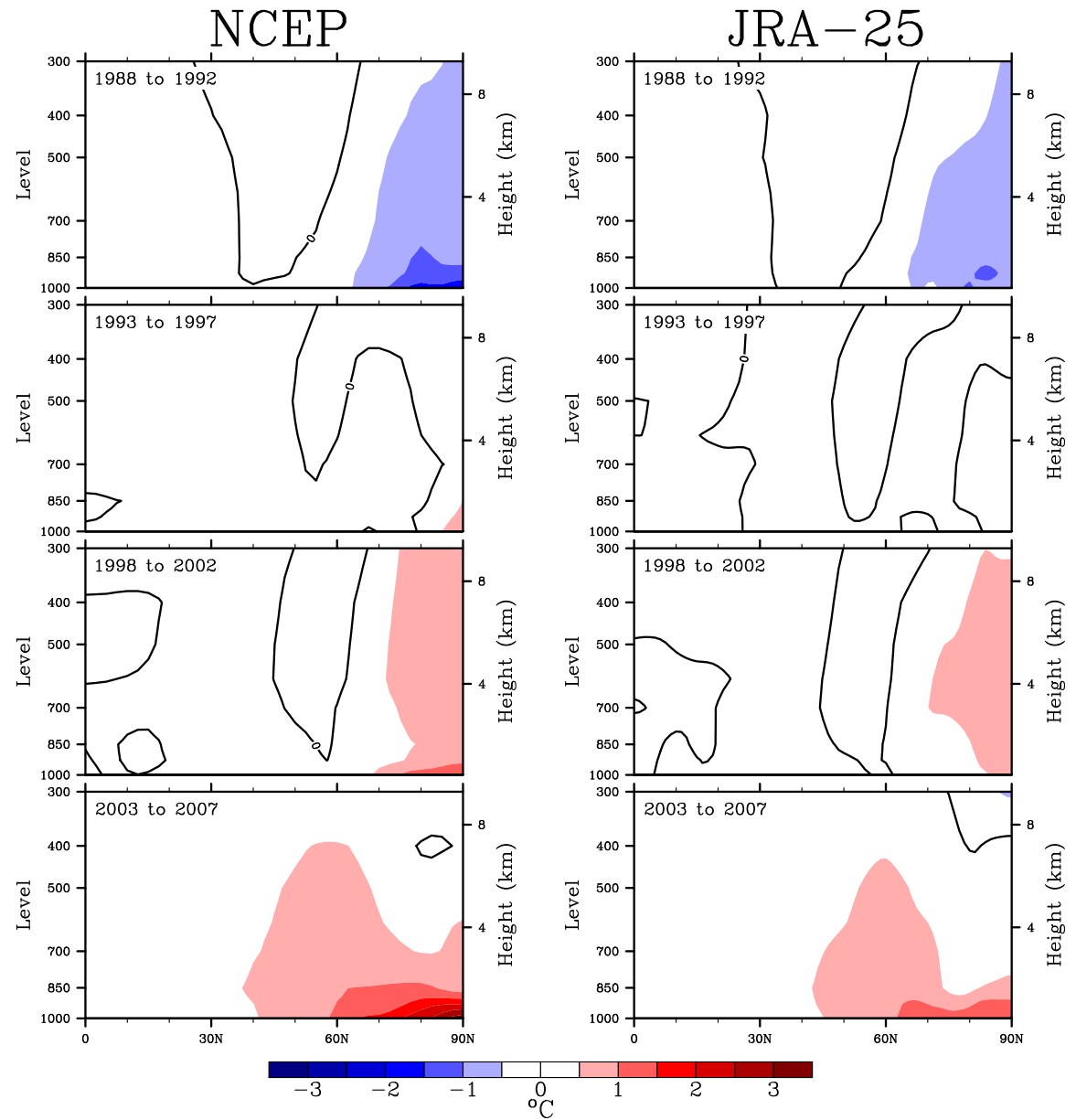

Fig. 6. Latitude by height (hPa) cross sections of autumn (September through November) zonally-averaged temperature anomalies, relative to 1979-2007 means for 1988-1992, 1993-1997, 1998-2002 and 2003-2007. Results based on NCEP are shown on the left and those based on JRA-25 are shown on the right.

Recall that Graversen et al. (2008), on the basis of ERA40 data from 1979-2001, found that recent Arctic amplification did not have a clear surface signature, pointing to increased atmospheric energy transport to the Arctic. The examples given above (see also Fig. 4) certainly point to imprints of circulation variability on the vertical temperature structure in the NCEP dataset. However, in autumn, and to a lesser extent, in winter, both the NCEP and JRA-25 data show these imprints as superimposed upon the effects of a growing anomalous surface heat source. Although differences between existing reanalyses in their depiction of the vertical structure of recent temperature change certainly exist, these differences, at least in the most recent pentad for NCEP and JRA-25, are not as striking as the results of trend analyses suggest (cf. Graversen et al., 2008). Nevertheless, the causes of differences between reanalysis remain to be resolved. Different approaches to the assimilation of satellite data is a prime candidate.

\section{Discussion and conclusions}

To summarize: 1) Starting in the late 1990s and relative to the 1979-2007 time period, Arctic Ocean SAT anomalies in the NCEP reanalysis turned positive in autumn and have subsequently grown; 2) Consistent with an anomalous surface heating source, development of the autumn warming pattern aligns with the observed reduction in September sea ice extent, and temperature anomalies strengthen from the lower troposphere to the surface; 3) Recent autumn warming is stronger in the Arctic than in lower latitudes; 4) Recent low level warming over the Arctic Ocean is less pronounced in winter when most open water areas have refrozen; 5) There is no enhanced surface warming in summer; 6) Conclusions 1-5 hold for both the NCEP and JRA-25 reanalyses, the major difference being that temperature anomalies in JRA-25 are somewhat smaller. 
We view these findings as consistent with the emergence of surface-based Arctic amplification associated with declining sea ice extent. Both reanalyses also show variable patterns of warming aloft in all seasons, pointing to imprints of large-scale atmospheric energy transport. In this respect our conclusions are not in conflict with those of Graversen et al. (2008).

It makes sense that the surface warming signal has emerged first in autumn. Less sea ice at summer's end (September), as observed, has enhanced upward heat fluxes to the atmosphere. Further analysis of the NCEP data reveals that the rise in Arctic Ocean SAT in autumn is most clearly linked to an increase in longwave radiation emitted by the surface, with changes in the turbulent sensible and latent heat fluxes playing a lesser role. Interestingly, the autumn net surface heat flux has shown little coherent change in the past decade. This follows in that while the warmer atmosphere radiates more strongly to the surface (by itself contributing to a more positive net surface heat flux), the surface in turn radiates more strongly to the atmosphere, with an opposing effect. Summer, by contrast, has seen a recent increase in the net surface heat flux (an increased net heat gain by the ice-ocean column). This is understood in that ice melt (phase change) and heating of the ocean mixed layer have limited the increase in the surface temperature and hence the upward longwave flux. With the expectation of continued summer ice loss, fostering more sensible heat gain in the upper ocean, autumn freeze-up will be further delayed, such that Arctic amplification should start to be seen in winter. The results in Fig. $2 b$ and $c$ hint that this winter signal is just emerging. Eventually, ice extent and thickness will be sufficiently reduced so that low-level warming will emerge in spring. This said, while the IPCC models consistently simulate fairly small increases in summer temperatures, the autumn peak in low-level warming seen in NCEP and JRA-25 is by no means universal across these climate models. For example, in CCSM3 (Fig. 1a), the magnitude of SAT anomalies are similar across the cold season months.

That the sea ice cover is responding to the effects of GHG loading finds strong support from analysis of the IPCC-AR4 simulations (e.g., Stroeve et al., 2007). Whether the warming seen in the NCEP and JRA-25 data is still within the expected range of natural variability is unclear. That the Arctic is home to strong variability is well recognized. For example, a period of strong high-latitude warming occurred from about 1930 to 1940 (Polyakov et al., 2002; Overland et al., 2004). While likely in part associated with reduced ice cover (Bengtsson et al., 2004), sparse data precludes drawing firm conclusions. As noted, the behavior of the Northern Annular Mode and other atmospheric patterns has contributed to sea ice loss observed over the satellite record and hence the rise in Arctic Ocean temperatures.

To gain some perspective on the expected natural variability, we analyzed 500 years of a pre-industrial CCSM3 control integrations with carbon dioxide fixed at 1870 levels. Over the domain used in Fig. 1 and for October (the month of maximum warming), CCSM3 simulates a standard deviation in SAT of $1.59^{\circ} \mathrm{C}$. To the extent that this simulation captures the unforced natural variability in the system, this suggests that the NCEP and JRA-25 anomalies in October SAT for even the last few years $\left(3-5^{\circ} \mathrm{C}\right)$ are extreme but may still be within bounds of natural variations. However, this is a conservative assessment since the observed anomalies are taken relative to a 1979-2007 time period which has likely already experienced anthropogenic warming. With models consistently simulating reductions of ice cover into the future, we view the emerging Arctic amplification documented in this paper as but a harbinger of a more pronounced signal to appear in the near future with impacts that may extend well beyond the Arctic Ocean (Lawrence et al., 2008).

Acknowledgements. This study was supported by NSF grants ARC-0531040, ARC-0531302, ATM-0531973, NASA grant NNG06GB26G and NOAA.

Edited by: E. Hanna

\section{References}

Arzel, O., Fichefet, T., and Goose, H.: Sea ice evolution over the 20th and 21st centuries as simulated by current AOGCMs, Ocean Model., 12, 201-415, 2006.

Bengtsson, L., Semenov, V. A., and Johannessen, O. M.: The early twentieth-century warming in the Arctic - a possible mechanism, J. Climate, 17, 4045-4057, 2004.

Francis, J. A. and Hunter, E.: New insight into the disappearing Arctic sea ice, EOS T. Am. Geophys. Un., 87, 509-511, 2006.

Graversen, R. G., Mauritsen, T., Tjernstrom, M., Kallen, E., and Svensson, G.: Vertical structure of recent Arctic warming, Nature, 451, 53-56, 2008.

Holland, M. M. and Bitz, C. M.: Polar amplification of climate change in coupled models, Clim. Dynam., 21, 221-232, 2003.

Holland, M. M., Bitz, C. M., and Tremblay, B.: Future abrupt reductions in the summer Arctic sea ice, Geophys. Res. Lett., 33, L23503, doi:10.1029/2006GL028024, 2006.

Kalnay, E., Kanamitsu, M., Kistler, R., et al.: The NCEP/NCAR 40-year reanalysis project, B. Am. Meteorol. Soc., 77, 437-471, 1996.

Kwok, R.: Nea zero replenishment of the Arctic multiyear sea ice cover at the end of 2005 summer, Geophys. Res. Lett., 34, L05501, doi:10.2029/2006GL028737, 2007.

Lawrence, D. M, Slater, A. G., Tomas, R., Holland, M. M., and Deser, C.: Accelerated Arctic land warming and permafrost degradation during rapid sea ice loss, Geophys. Res. Lett., 35, L11506, doi:10.1029/2008GL033985, 2008.

Manabe, S. and Stouffer, R. J.: Sensitivity of a global climate model to an increase of $\mathrm{CO}_{2}$ in the atmosphere, J. Geophys. Res. 85(C10), 5529-5554, 1980.

Maslanik, J., Drobot, S., Fowler, C., Emery, W., and Barry, R.: On the Arctic climate paradox and the continuing role of atmospheric circulation in affecting sea ice conditions, Geophys. Res. Lett., 34, L03711, doi:10.1029/2006GL028269, 2007a. 
Maslanik, J. A., Fowler, C., Stroeve, J., Drobot, S., Zwally, H. J., Yi, D., and Emery, W. J.: A younger, thinner ice cover: Increased potential for rapid, extensive ice loss, Geophys. Res. Lett., 34, L24501, doi:10.1029/2007GL032043, 2007b.

Nghiem, S. V., Chao, Y., Neumann, G., Li, P., Perovich, D. K., Street, T., and Clemente-Colon, P.: Depletion of perennial sea ice in the East Arctic Ocean, Geophys. Res. Lett., 33, L17501, doi:10.1029/2006GL027198, 2006.

Onogi, K., Koide, H., Sakamoti, M., Kobayashi, S., et al.: JRA-25: Japanese 25-year re-analysis project - progress and status, Q. J. Roy. Meteor. Soc., 131, 3259-3268, 2005.

Onogi, K., Tsutsui, J., Koide, H., Sakamoto, M., Kobayashi, S., Hatsushika, H., Matsumoto, T., Yamazaki, S., Kamahori, H., Takahashi, K., Kadokura, S., Wada, K., Kato, K., Oyama, R., Ose, T., Mannoji, N., and Taira, R.: The JRA-25 reanalysis, J. Meteorol. Soc. Jpn., 85, 369-432, 2007.

Overland, J. E., Spillane, M. C., Percival, D. B., Wang, M., and Mofjeld, H. O.: Seasonal and regional variation of pan-Arctic surface air temperature over the instrumental record, J. Climate, 15, 3263-3282, 2004.

Polyakov, I. V., Alekseev, G. V., Bekryaev, R. V., Bhatt, U., Colony, R., Johnson, M. A., Karklin, V. P., Makshtas, A. P., Walsh, J., and Yulin, A. V.: Observationally based assessment of polar amplification of global warming, Geophys. Res. Lett., 29, 1878, doi:10.1029/2001GL011111, 2002.

Polyakov, I. V., Beszezynska,A., Carmack, E., et al.: One more step toward a warmer Arctic, Geophys. Res. Lett., 32, L17605, doi:10.1029/2005GL023740, 2005.

Rigor, I. G. and Wallace, J. M.: Variations in the age of Arctic seaice and summer sea-ice extent, Geophys. Res. Lett., 31, L09401, doi:10.1029/2004GL019492, 2004.
Rigor, I. G., Wallace, J. M., and Colony, R. L.: Response of sea ice to the Arctic Oscillation, J. Climate, 15, 2648-2663, 2002.

Serreze, M. C. and Francis, J. A.: The Arctic amplification debate, Climatic Change, 76, 241-264, 2006.

Serreze, M. C., Barrett, A. P., Slater, A. J., Steele, M., Zhang, J., and Trenberth, K. E.: The large-scale energy budget of the Arctic, J. Geophys. Res., 112, D11122, doi:10.1029/2006JD008230, 2007a.

Serreze, M. C., Holland, M. M., and Stroeve, J.: Perspectives on the Arctic's shrinking sea ice cover, Science, 315, 1533-1536, $2007 b$.

Shimada, K., Kamoshida, T., Itoh, M., Nishino, S., Carmack, E., McLaughlin, F., Zimmerman, S., and Proshutinsky, A.: Pacific Ocean inflow: Influence on catastropic reduction of sea ice cover in the Arctic Ocean, Geophys. Res. Lett., 33, L08605, doi:10.1029/2005GL025624, 2006.

Stroeve, J., Holland, M. M., Meier, W., Scambos, T., and Serreze, M.: Arctic sea ice decline: Faster than forecast, Geophys. Res. Lett., 34, L09501, doi:10.1029/2007GL029703, 2007.

Stroeve, J., Serreze, M., Drobot, S., Gearheard, S., Holland, M., Maslanik, J., Meier, W., and Scambos, T.: Arctic sea ice extent plummets in 2007, EOS T. Am. Geophys. Un., 89, 13-14., 2008.

Thompson, D. W. J and Wallace, J. M.: The Arctic Oscillation signature in the wintertime geopotential height and temperature fields, Geophys. Res. Lett., 25, 1297-1300, 1998.

Uppala, S., Kalberg, P. W., Simmons, A. J., et al.: The ERA-40 re-analysis, Q. J. Roy. Meteor. Soc., 131, 2961-3102, 2005.

Zhang, X. and Walsh, J. E.: Toward a seasonally ice-covered Arctic Ocean: Scenarios from the IPCC AR4 model simulations, J. Climate, 19, 1730-1747, 2006. 